\title{
Purpureonostoc, a new name for a recently described genus of Nostoc-like cyanobacteria
}

\author{
Fangfang CAI \& Renhui LI
}

\begin{abstract}
Key Laboratory of Algal Biology, State Key Laboratory of Freshwater Ecology and Biotechnology of China, Institute of Hydrobiology, Chinese Academy of Sciences, Wuhan 430072, People's Republic of China; e-mail: reli@ihb.ac.cn
\end{abstract}

\begin{abstract}
A new cyanobacterial genus was recently named Purpurea, based on morphology, 16S rRNA gene sequence and 16-23S ITS secondary structure, which differentiated it from the other Nostoc-like genera (CAI et al. 2020). The designation "Purpurea" is invalid as it is contrary to Art. 20.2 (Art. 20.2. "The name of a genus may not coincide with a Latin technical term in use in morphology at the time of publication unless it was published before 1 January 1912."). As this new genus is similar to Nostoc, "Purpurea F. Cai et R. Li" nom. inval. is here renamed as Purpureonostoc.
\end{abstract}

Key words: Cyanobacteria, Purpurea, $16 \mathrm{~S}$ rRNA gene, Purpureonostoc

Purpureonostoc F.F.Cai et R.H.Li gen. nov.

Replaced designation: "Purpurea F.F. Cai et R.H. Li"

(CAI et al. (2020), nom. inval.).

Description: CAI et al. (2020).

Type species: Purpureonostoc tibetica F. Cai et R. Li, below.

Purpureonostoc tibetica F.F. Cai et R.H. Li sp. nov. Replaced binary designation: Purpurea tibeticum F. Cai et R. Li (CAI et al. (2020), nom. inval.).

Description: CAI et al. (2020).

Holotype: HBI! No. TBCN201701 dry material deposited in the Freshwater Algal Herbarium, Institute of Hydrobiology, Chinese Academy of Science, Wuhan, China.

Type locality: Isolated from the wet soil samples in Tibet, China (3046'32.90"N, 9052'14.78"E).
ACKNOWLEDGEMENTS

We are grateful to Michael Guiry, Petr Hašler and Aloisie Poulickova for nomenclatural advice.

\section{REFERENCES}

Cai, F.; Wang, Y.; Yu, G.; Wang, J.; Pen, X. \& Li, R. (2020): Proposal of Purpurea gen. nov. (Nostocales, Cyanobacteria), a novel cyanobacterial genus from wet soil samples in Tibet, China. - Fottea 20: 86-97.

(C) Czech Phycological Society (2020)

Received March 1, 2020

Accepted May 29, 2020 